\title{
Bilingualism delays the onset of behavioral but not aphasic forms of Frontotemporal Dementia
}

Suvarna Alladi ${ }^{\mathrm{a}}$, $^{*}$, Thomas H Bak ${ }^{\mathrm{b}}$, Mekala Shailaja ${ }^{\mathrm{a}}$,

Divyaraj Gollahallia ${ }^{\mathrm{a}}$, Amulya Rajan ${ }^{\mathrm{a}}$, Bapiraju Surampudi ${ }^{\mathrm{c}}$, Michael

Hornberger $^{\mathrm{d}}$,Vasanta Duggirala ${ }^{\mathrm{e}}$, Jaydip Ray Chaudhuri ${ }^{\mathrm{f}}$, Subhash Kaul ${ }^{\mathrm{a}}$

\author{
a Department of Neurology, Nizam's Institute of Medical Sciences, Punjagutta, \\ Hyderabad, India-500082 \\ ${ }^{\mathrm{b}}$ Department of Psychology, Centre for Cognitive Aging and Cognitive \\ Epidemiology (CCACE) and Centre for Clinical Brain Sciences (CCBS), University \\ of Edinburgh, Edinburgh, UK \\ ${ }^{c}$ Cognitive Science lab, International Institute of Information Technology, Hyderabad \\ $\&$ Centre for Neural and Cognitive Sciences, University of Hyderabad, Hyderabad, \\ India \\ ${ }^{\mathrm{d}}$ Norwich Medical School, University of East Anglia, UK \\ ${ }^{e}$ Department of Linguistics, Osmania University, Hyderabad, India. \\ ${ }^{\mathrm{f}}$ Department of Neurology, Yashoda Hospitals, Hyderabad, India
}

\section{*Corresponding Author:}

Dr.Suvarna Alladi

Professor

Department of Neurology

National Institute of Mental Health and Neurosciences

Hosur Road, Lakkasandra,

Bengaluru, Karnataka 560029, India

Mobile: 00919866064304

Email: alladisuvarna@hotmail.com

\section{Authors email addresses}

1. Suvarna Alladi; Email: alladisuvarna@ hotmail.com

2. Thomas H Bak; Email: thomas.bak@ed.ac.uk

3. Mekala Shailaja; Email: shailaja1.mekala@gmail.com

4. Divyaraj Gollahalli; Email: diya174@gmail.com

5. Amulya Rajan; Email: amulya.rajan@gmail.com

6. Bapiraju Surampudi; Email: raju.bapi@iiit.ac.in

7. Michael Hornberger; Email: m.hornberger@uea.ac.uk

8. Vasanta Duggirala; Email:vasantad@gmail.com

9. Jaydip Ray Chaudhuri; Email: jaydiprc@ gmail.com

10. Subhash Kaul; Email: subashkaul@ hotmail.com

\footnotetext{
${ }^{1}$ Present address: Department of Neurology, National Institute of Mental Health and Neurosciences, Hosur Road, Lakkasandra, Bengaluru, Karnataka 560029, India
} 


\section{Author contributions}

Suvarna Alladi contributed to study conception and design, literature search, subject recruitment, data collection, analysis and interpretation, writing of manuscript.

Thomas H Bak contributed to literature search, data interpretation, writing of manuscript.

Mekala Shailaja contributed to literature search, data collection, analysis and interpretation, writing of manuscript.

Divyaraj Gollahalli contributed to literature search, data analysis and interpretation, writing of manuscript.

Amuya Rajan contributed to literature search, data analysis and interpretation, writing of manuscript.

Bapi Raju Surampudi contributed to literature search, data interpretation, editing of manuscript.

Michael Hornberger contributed to data analysis and interpretation, editing of manuscript.

Vasanta Duggirala contributed to literature search, data interpretation, editing of manuscript.

Jaydip Ray Chaudhuri contributed to study design, subject recruitment, data interpretation, editing of manuscript.

Subhash Kaul contributed to study design, subject recruitment, data interpretation, editing of manuscript

\section{Disclosure Statements:}

Suvarna Alladi reports no disclosures

Thomas H Bak reports no disclosures

Mekala Shailaja received research fellowship from Department of Science and

Technology, Cognitive Science Research Initiative, Government of India

Divyaraj Gollahalli received research fellowship from Indian Council for Medical

Research, Government of India

Amulya Rajan reports no disclosures

Bapi Raju Surampudi reports no disclosures

Michael Hornberger reports no disclosures

Vasanta Duggirala reports no disclosures 
Jaydip Ray Chaudhuri reports no disclosures

Subhash Kaul reports no disclosures

This work was supported by the Department of Science and Technology, Cognitive Science Research Initiative, Government of India [Grant no SR/CSI/43/2008].

Word count of the abstract: 279

Word count of the paper: 3125

Number of references:39

Number of tables: 3

\begin{abstract}
Bilingualism has been found to delay onset of dementia and this has been attributed to an advantage in executive control in bilinguals. However, the relationship between bilingualism and cognition is complex, with costs as well as benefits to language functions. To further explore the cognitive consequences of bilingualism, the study used Frontotemporal dementia (FTD) syndromes, to examine whether bilingualism modifies the age at onset of behavioural and language variants of Frontotemporal dementia (FTD) differently. Case records of 193 patients presenting with FTD (121 of them bilingual) were examined and the age at onset of the first symptoms were compared between monolinguals and bilinguals. A significant effect of bilingualism delaying the age at onset of dementia was found in behavioural variant FTD (5.7 years) but not in progressive nonfluent aphasia ( 0.7 years), semantic dementia $(0.5$ years), corticobasal syndrome (0.4 years), progressive supranuclear palsy (4.3 years) and FTD-motor neuron disease (3 years). On dividing all patients predominantly behavioral and predominantly aphasic groups, age at onset in the bilingual behavioral group (62.6) was over 6 years higher than in the monolingual patients $(56.5, \mathrm{p}=0.006)$,
\end{abstract}


while there was no difference in the aphasic FTD group (60.9 vs. 60.6 years, $\mathrm{p}=0.851$ ). The bilingual effect on age of bvFTD onset was shown independently of other potential confounding factors such as education, gender, occupation, and urban vs rural dwelling of subjects. To conclude, bilingualism delays the age at onset in the behavioral but not in the aphasic variants of FTD. The results are in line with similar findings based on research in stroke and with the current views of the interaction between bilingualism and cognition, pointing to advantages in executive functions and disadvantages in lexical tasks.

Key words: Dementia, Frontotemporal dementia, Executive function, Aphasia, Bilingualism

\section{Introduction}

Current research suggests that the clinical expression of dementia is modifiable by lifelong factors protecting against cognitive decline by enhancing the "cognitive reserve" (Stern, 2002). One of potential protective factors is bilingualism, reported to improve cognitive functioning in healthy ageing (Bak 2014 et al., 2014) and to delay the onset of dementia by 4-5 years (Bialystok et al., 2007; Woumans et al., 2015). Although the mechanism and degree of this effect remain controversial (Freedman et al., 2014), the cognitive domain implicated most consistently are executive functions (Valian, 2015). In contrast, a well-documented cognitive cost of bilingualism is slowing in lexical tasks, such as picture naming (Gollan et al., 2005).

Accordingly, we can expect bilingualism to have different effects on brain diseases depending on the cognitive domains involved, with strongest positive effects on executive and weakest on language function. Indeed, such a pattern was found recently in stroke patients: bilinguals had a lower frequency of post-stroke dementia 
and mild cognitive impairment than monolinguals, but the same frequency of aphasia (Alladi et al., 2016). Likewise, the only study to date examining systematically the relation between bilingualism and different types of dementia found the longest bilingualism-related delay in dementia onset in frontotemporal dementia (FTD), a disease characterized by a prominent frontal-executive dysfunction (Alladi et al., 2013).

The present study goes one step further by examining the effects of bilingualism on the onset of different variants of FTD: the behavioral variant (Rascovsky et al., 2011), progressive aphasias (Gorno-Tempini et al., 2011) as well as associated movement disorders: corticobasal degeneration, progressive supranuclear palsy and motor neuron disease (Bak, 2010; Kertesz, 2003). We hypothesise that the beneficial effect of bilingualism will be largest in the behavioral and smallest (or absent) in the aphasic forms of FTD.

\section{Methods}

\subsection{Patients and diagnosis}

Case records of 193 consecutive FTD patients diagnosed in a specialist clinic located in Hyderabad, between 2006 and 2015 were reviewed. All patients were participants in an ongoing longitudinal dementia registry project. All subjects were evaluated by an experienced behavioral neurologist (S.A.) using a diagnostic protocol adapted from the Cambridge Memory Clinic model (Hodges et al., 2000). The assessments were performed by trained psychologists using a structured procedure. The Mini-Mental State Examination and Addenbrooke's Cognitive Examination- revised (ACE-R), were adapted for Telugu, Dakkhini, and Hindi speaking populations of Hyderabad 
(Alladi et al., 2016). The Clinical Dementia Rating (CDR) scale was used to determine severity of dementia. Additional diagnostic tests used were Frontal Systems Behavior Scale (FrSBe) (Grace et al., 1999) to identify frontal behaviors and the Indian adaptation of the Cambridge semantic battery test (Alladi et al., 2010) to diagnose language and semantic memory deficits.

Patients were diagnosed on the basis of clinical features at first presentation to the clinic. The presence of amnesia, aphasia, visuospatial deficits, changes in social behavior, frontal behaviors, specifically apathy, disinhibition and executive dysfunction, stereotypic behaviors, apraxia, other neuropsychiatric features; delusions, hallucinations, agitation and depression and motor signs; extrapyramidal features, bulbar and pyramidal involvement, were recorded in all patients. Diagnosis of FTD was made based on FTLD consensus criteria (Neary et al., 1998) and patients were categorized into subtypes of behavioral variant FTD (bvFTD) and two aphasic variants: progressive nonfluent aphasia (PNFA) and semantic dementia (SD). In addition, we included patients with three motor syndromes associated with FTD as part of the 'Pick Complex' (Kertesz, 2003, Strong et al., 2009): frontotemporal dementia- motor neuron disease (FTD-MND) (Strong et al., 2009), corticobasal degeneration (CBD) (Armstrong et al., 2013) and progressive supranuclear palsy (PSP) (Litvan et al., 1996). All FTD-MND, CBD and PSP patients included in this study presented with early FTD features as well as motor features. In contrast to the bvFTD with its behavioral presentation and SD and PNFA with their aphasic features, the motor variants of FTD can be characterised by a behavioral or aphasic clinical picture, as well as a combination of both (Burrell et al., 2016; Sha et al., 2006). Therefore, we divided patients into two groups: predominantly behavioral $(n=90)$ in 
subjects with frontal behavioral symptoms of apathy, disinhibition or executive dysfunction at first presentation and predominantly aphasic $(n=95)$ in subjects with predominant language impairment on history or on language tests), excluding those in whom both types of symptoms were equally pronounced based on available clinical information $(n=8)$.

\subsection{Data collection and evaluation}

Case records were reviewed by research fellows who were not involved in data collection (AR and DR) for the following details: age of patient, sex, age at onset of dementia, educational status, bilingualism, occupation and family history of dementia. All information was obtained from a reliable family member. Age at onset of dementia was defined as the age at which the first clinical symptom suggestive of dementia was noticed. Bilingualism was defined as the ability to communicate in two or more languages in interaction with other speakers of these same languages (Mohanty, 1994). Educational status was derived from years of formal education received. Illiterate individuals were defined as those who had no formal education and were unable to read and write in any language. In keeping with the skill levels defined to suit Indian conditions, we used the National Classification of Occupations-2004 to classify subjects into different occupational statuses. The institutional ethics committee of Nizam's Institute of Medical Sciences approved the study.

\subsection{Statistical analysis}

Clinical and demographic characteristics of FTD subtypes and monolingual and bilinguals were compared using independent samples t test/One-way analysis of variance for continuous variables and chi-square test for categorical variables. 
Posthoc tests were done using Bonferroni adjustments for continuous variables. A univariate general linear model (GLM) was used to assess the effect of bilingualism on age at onset of dementia in bvFTD after adjusting for years of education, literacy, occupation, gender, rural/urban dwelling and family history of dementia. Interaction effects of bilingualism with these various demographic and clinical variables were also calculated by using univariate GLM. Statistical analysis was performed using SPSS 20.0 for windows software (SPSS Inc., Chicago, IL).

\section{Results}

\subsection{Clinical and demographic characteristics of the study cohort}

A total of 193 patients were diagnosed with FTD during the study period (Table 1). The most common diagnosis was bvFTD in 67 patients $(34.7 \%)$, followed by PNFA in $39(20.2 \%)$, PSP in $31(16.1 \%)$, SD in $23(11.9 \%)$, CBD in $23(11.9 \%)$, and FTDMND in $10(5.2 \%)$. The mean age at presentation was 63.0 years (SD 9.5, Range $=40-$ 91 years); bvFTD and FTD-MND patients tended to be younger at presentation than the other groups, but this trend did not reach significance. The proportion of men/women was $57.5 \%$ versus $42.5 \%$; 172 patients (89.1\%) were literate. Mean duration of symptoms was 2.5 years and was significantly shorter in the motor presentations of FTD: CBD, PSP and FTD- MND than in the classical behavioral and aphasic variants. Family history of dementia in a first degree relative was present in 38 patients $(19.7 \%) ; 23$ of them were in patients with bvFTD.

\subsection{Comparison of monolingual and bilingual patient groups}

Hundred twenty one patients (62.7\% of the cohort) were bilingual, of whom 48 spoke two languages and 73 three or more languages. The most commonly encountered 
language combinations were Telugu and Hindi, Telugu, English and Hindi, and Telugu and Dakkhini. The severity of dementia as measured by ACE-R and CDR was not different between mono and bilinguals. There was also no difference in the duration of illness, and family history of dementia between the two groups (Table 2). The bilingual cohort had more men, more literate individuals, and higher skill levels in their occupation compared with monolinguals. Overall, bilinguals were found to be 3.3 years older at the time of occurrence of the first symptoms of dementia: 61.7 years in bilinguals as opposed to 58.4 years in monolinguals $(\mathrm{p}=0.017)$. However, as will be described below, the age at diagnosis and the bilingualism effect modulating it, varied across different diagnoses.

\subsection{Relationship between bilingualism and the type and age at onset of dementia}

We compared the age at onset of dementia between monolinguals and bilinguals within FTD subtypes (Table 3). Bilingual patients with bvFTD had a 5.7 year delay in age at onset compared to monolinguals $(\mathrm{p}=0.024)$. In contrast, there was no significant difference between monolinguals and bilinguals in the age at onset of PNFA, SD, FTD-MND, CBD, and PSP. Further, since the three motor syndromes CBD, PSP and FTD-MND included in our analysis are characterised by a behavioral or aphasic clinical picture, as well as a combination of both, we divided all patients based on the profile of symptoms into predominantly behavioral and predominantly aphasic. Both groups had comparable size ( $n=91$ vs $n=97$ ). The results showed the same pattern as in the first analysis: age at onset in the bilingual behavioral group (62.6 years) was over 6.1 years higher than in the monolingual patients (56.5 years, $\mathrm{p}=0.006$ ). In contrast, there was no difference in the age at onset between the monoand bilinguals in the aphasic FTD groups (60.9 vs. 60.6 years, $\mathrm{p}=0.851)$. 
We explored the association between age at onset of FTD subtypes and a range of demographic and clinical variables. Factors that were found to be associated with age at onset of bvFTD were bilingualism (monolinguals mean age at onset 55.3 vs bilingual mean age at onset 61.0), rural dwelling (rural dwellers mean age at onset 53.8 vs urban dwellers mean age at onset 60.8 ), and literacy (illiterates mean age at onset 50.3 vs literates mean age at onset 59.6). None of the factors were significantly associated with age at onset in other subtypes of FTD. Univariate GLM analysis showed that bilingualism was significantly $\left(\mathrm{F}_{1,25}=7.74, \mathrm{p}=0.010\right)$ associated with age at onset of bvFTD after adjusting for the other variables such as years of education, literacy, occupation, gender, rural/urban dwelling and family history of dementia. To assess the effect of interaction between bilingualism and these factors on age at onset of bvFTD we used univariate GLM. We found no interaction effects of years of education $\left(\mathrm{F}_{1,65}=0.57, \mathrm{p}=0.57\right)$, literacy $\left(\mathrm{F}_{1,65}=0.005, \mathrm{p}=0.94\right)$, occupational status $\left(F_{2,38}=0.52, p=0.67\right)$, gender $\left(F_{1,65=1.40, p}=0.27\right)$, rural/ urban dwelling $\left(F_{1,58}=0.89\right.$, $\mathrm{p}=0.42)$, and family history $\left(\mathrm{F}_{1,65}=0.71, \mathrm{p}=0.50\right)$.

\section{To explore a possible additive effect of number of languages, we examined the} differences between 2 vs 3 or more languages in FTD patients with predominantly behavioural presentation. Results of the analysis suggested that there was no significant difference in age at onset between those that spoke 2 vs 3 or more languages (61.7 vs 63.3 years, $\mathrm{p}=0.576)$ 


\section{Discussion}

We present the first study looking specifically at the bilingualism effects on different subtypes of FTD. In a previous publication we have demonstrated that the delay in onset of dementia associated with bilingualism and first described by Bialystok et al in 2007 (Bialystok et al., 2007) varies between different types of dementia: it is most pronounced in FTD, followed by AD dementia and vascular dementia and does not reach significance in Dementia with Lewy Bodies (Alladi et al., 2013). In this study we found that the bilingual delay in onset of dementia in FTD is entirely due to the behavioral variant of the disease and does not extend to its aphasic variants. The effect of bilingualism was found to be independent of other factors affecting age at onset such as education and rural dwelling.

We compared 6 distinct diagnostic categories of the FTD-spectrum: bvFTD, the two classical aphasic FTD variants (PNFA and SD) and the three motor disorders associated with a FTD-like cognitive and behavioral presentation: CBD, PSP and FTD-MND. The only diagnosis in which we found a significant difference in the age at onset between mono and bilinguals was bvFTD. In contrast, the age at onset in SD, CBD and PNFA was virtually the same $(0.5,0.4$ and 0.7 years of difference respectively). The difference in FTD-MND (3 years) and PSP (4.3 years) was bigger, but did not reach significance, which could have also been influenced by the smaller size of these two groups. However, on classifying the entire cohort including the motor syndromes into behavioural and aphasic presentations, we found again a similar pattern: a delayed age at onset was observed in the behavioural but not aphasic presentations. Thus, both a syndrome-based (variants of FTD) and a symptom-based (predominantly behavioural vs. predominantly motor presentation) analysis produce a 
very similar result: an effect of bilingualism on the behavioural but not the aphasic form of FTD.

Our study shows that the effect of bilingualism on the onset of dementia depends critically on the exact diagnosis and presentation. Taking this factor into account could explain some of the conflicting evidence reported in this field. Some of the recent longitudinal studies which report no differences between mono- and bilinguals included only participants over the age of 65 (Zahodne et al., 2014): given the early age at presentation of bvFTD, such a study protocol will selectively exclude exactly the patient group which is more likely to show bilingual benefits. Even more pronounced confounding effects can occur in studies which do not distinguish between different types of dementia. Patients with progressive aphasia are often misdiagnosed as having dementia or AD dementia; indeed, at least one type of progressive aphasia (so called "logopenic aphasi") can be associated with Alzheimertype pathology (Gorno-Tempini et al., 2011). Future studies exploring the relationship between bilingualism and dementia need to aim not only at large number of patients but also at their detailed phenotypic characterisation. The same is true for studies of Mild Cognitive Impairment (MCI), where the effects of bilingualism can vary between patients with single- and multidomain MCI (Ossher et al., 2013).

The observation that bilingualism has a positive effect on behavioral syndromes (but not on language disorders) is consistent with the current understanding of the effects of bilingualism on cognition. Whatever controversy there might exist about the presence, magnitude and mechanism of the interaction between bilingualism and cognition, the most consistent positive effects have been reported in executive 
functioning (Bak, 2016). Early bvFTD is characterised by behavioural symptoms, social cognition and delayed reward gratification problems; however, patients often perform in the normal range on traditional frontal-executive tests at this stage (Bozeat et al., 2000; Gregory and Hodges,1996). This correlates with imaging studies, demonstrating that, in the initial stages of disease of bvFTD, anterior cingulate cortex, frontal insular and orbitofrontal regions are first affected, while the dorsolateral prefrontal cortex region involved only later with disease progression (Seeley et al., 2008). Hence, in the early, pre-diagnostic stages of bvFTD, the dorso-lateral prefrontal cortex (DLPFC), associated with classic executive functions such as attention switching remains intact and can compensate to a certain degree for more anterior and medial frontal deficits. On the other hand, in diseases with an early and prominent involvement of executive and attentional processes, bilingualism might not be able to exert much compensatory influence, as seems to be the case in Attention deficit hyperactivity disorder (Bialystok et al., 2016), multi-domain MCI (Ossher et al., 2013) and Dementia with Lewy Bodies (Alladi et al., 2013).

In contrast, the effects of bilingualism on language functions are more complex and not always beneficial. Smaller vocabulary size and slower lexical processing, manifesting itself in worse performance on tasks such as verbal fluency and picture naming can be seen as the "cognitive cost" of bilingualism and have been well documented in healthy controls (Bialystok, 2009; Gollan et al., 2005). Since PNFA is typically associated with reduced fluency and SD with a breakdown of semantic system and pronounced deficits in object naming (Gorno-Tempini et al., 2011), a premorbid bilingual cost to these language functions is likely to potentiate the effects of pathology. Any advantage to executive functioning or inhibitory control that may 
have occurred due to bilingualism has probably been offset by a cost to linguistic processing, resulting in the absence of an overall protective effect for bilingual patients with PNFA and SD. Since language functions are relatively spared in bvFTD, the linguistic cost probably does not impact clinical expression in these patients. Interestingly, a similar observation was made recently in stroke patients: when compared to monolinguals, bilinguals had a significantly lower frequency of poststroke dementia and mild cognitive impairment but the same frequency of post-stroke aphasia (Alladi et al., 2016).

Obviously, bilingualism is bound to interact with many other factors, biological as well as social and cultural. Two factors which received recently special attention in this context are immigration and education (Bak and Alladi, 2016). The first one does not play a major role in the population investigated in this study: frequent bilingualism has characterised life of most people in Hyderabad for many centuries and is not associated with recent immigration. Moreover, several studies from other countries also show that bilingualism effects do not depend on immigration status (Bak et al., 2014; Woumans et al., 2015). The relationship between bilingualism, education and the age at onset of dementia is more complex (Iyer et al., 2014). A protective role of education and occupation has been reported in dementia in general and in FTD in particular ( Borroni et al., 2009; Premi et al., 2013). However, a positive effect of education has been complex and might well depend on interaction with other variables (Sharp and Gatz, 2011). Indeed, in a recent study in Indian context education seems to play a smaller role than bilingualism (Iyer et al., 2014). While education, bilingualism and rural dwelling were associated in a delay in onset of bv FTD, only bilingualism had an independent effect with no interactions with other factors. 
Limitations of the study include its retrospective nature, and the clinic base of patient population. FTD is however a relatively rare diagnosis and studying such large numbers in the community would not be feasible. Moreover, bilingualism was defined as a dichotomous variable, based on a subjective measure of communicative ability. Ideally, bilingualism should be defined by objective as well as subjective measures and treated as a continuous rather than a categorical variable since increasing evidence suggests that language proficiency and use are on a continuum, particularly in populations such as in India (Naik et al., 2016; Vasanta, 2011). However, recent studies in other populations have demonstrated that subjective assessment of language ability can correlate remarkably well with objective measures of language proficiency (Vega-Mendoza et al., 2015).

In conclusion, using the neurodegenerative disorder FTD as a model to study cognitive consequences of bilingualism, our results provide further evidence that bilingualism has a protective effect against dementia, but also suggest that this effect is domain-specific. The beneficial effect appears to act through enhancement of executive functions and is associated with a concurrent disadvantage to language functions. We believe that our results further our understanding of the mechanisms underlying the cognitive consequences of bilingualism, with implications for the phenomenon of cognitive reserve in general.

\section{References}

Alladi, S., Bak, T.H., Duggirala, V., Surampudi, B., Shailaja, M., Shukla, A.K., Chaudhuri, J.R., Kaul, S., 2013. Bilingualism delays age at onset of dementia, independent of education and immigration status. Neurology. 81, 1938-1944. 
Alladi, S., Bak, T.H., Mekala, S., Rajan, A., Chaudhuri, J.R., Mioshi, E., Krovvidi, R., Surampudi, B., Duggirala, V., Kaul, S., 2016. Impact of bilingualism on cognitive outcome after stroke. Stroke. 47, 258-261.

Alladi, S., Mridula, R., Mekala, S., Rupela, V., Kaul, S., 2010. Fluent Aphasia in Telugu: A Case Comparison Study of Semantic Dementia and Stroke Aphasia. Indian J Appl Linguist. 36, 133-146.

Armstrong, M.J., Litvan, I., Lang, A.E., Bak, T.H., Bhatia, K.P., Borroni, B., Boxer, A.L., Dickson, D.W., Grossman, M., Hallett, M., Josephs, K.A., 2013. Criteria for the diagnosis of corticobasal degeneration. Neurology. 80. 496-503.

Bak, T.H., 2016. Cooking pasta in La Paz. Linguistic Approaches to Bilingualism. 6, 699-717.

Bak, T.H., 2011. Movement disorders: why movement and cognition belong together. Nat Rev Neurol. 7, 10-12.

Bak, T.H., Alladi, S., 2016. Bilingualism, dementia and the tale of many variables: Why we need to move beyond the Western World. Commentary on Lawton et al.(2015) and Fuller-Thomson (2015). Cortex. 74, 315-317.

Bak, T.H., Nissan, J.J., Allerhand, M.M., Deary, I.J., 2014. Does bilingualism influence cognitive aging? Ann. Neurol. 75, 959-963.

Bialystok, E., 2009. Bilingualism: The good, the bad, and the indifferent. Bilingualism: Language and cognition. 12, 3-11.

Bialystok, E., Craik, F.I., Freedman, M., 2007. Bilingualism as a protection against the onset of symptoms of dementia. Neuropsychologia. 45, 459-464.

Bialystok, E., Hawrylewicz, K., Wiseheart, M., Toplak, M., 2016. Interaction of bilingualism and Attention-Deficit/Hyperactivity Disorder in young adults. Bilingualism: Language and Cognition. 1-14.

Borroni, B., Premi, E., Agosti, C., Alberici, A., Garibotto, V., Bellelli, G., Paghera, B., Lucchini, S., Giubbini, R., Perani, D., Padovani, A., 2009. Revisiting brain reserve hypothesis in frontotemporal dementia: evidence from a brain perfusion study. Dement Geriatr Cogn Disord. 28, 130-135.

Bozeat, S., Gregory, C.A., Ralph, M.A.L., Hodges, J.R., 2000. Which neuropsychiatric and behavioural features distinguish frontal and temporal variants of frontotemporal dementia from Alzheimer's disease?. J Neurol Neurosurg Psychiatry. 69, 178-186.

Burrell, J.R., Halliday, G.M., Kril, J.J., Ittner, L.M., Götz, J., Kiernan, M.C., Hodges, J.R., 2016. The frontotemporal dementia-motor neuron disease continuum. Lancet. 388 , 919-931. 
Freedman, M., Alladi, S., Chertkow, H., Bialystok, E., Craik, F.I.M., Phillips, N.A., Duggirala, V., Raju, S.B., Bak, T.H., 2014. Delaying onset of dementia: Are two languages enough? Behav. Neurol. 2014, 2014.

Gollan, T.H., Montoya, R.I., Fennema-Notestine, C., Morris, S.K., 2005. Bilingualism affects picture naming but not picture classification. Mem. Cognit. 33, 12201234.

Gorno-Tempini, M.L., Hillis, A.E., Weintraub, S., Kertesz, A., Mendez, M., Cappa, S.E.E.A., Ogar, J.M., Rohrer, J.D., Black, S., Boeve, B.F., Manes, F., 2011. Classification of primary progressive aphasia and its variants. Neurology. 76, 1006-1014.

Grace, J., Stout, J.C., Malloy, P.F., 1999. Assessing frontal lobe behavioral syndromes with the frontal lobe personality scale. Assessment. 6, 269-284.

Gregory, C.A., Hodges, J.R., 1996. Clinical features of frontal lobe dementia in comparison to Alzheimer's disease. J Neural Transm Suppl. 47, 103-123.

Hodges, J.R., Berrios, G., Breen, K., 2000. The multidisciplinary memory clinic approach. Memory disorders in psychiatric practice.101-121.

Iyer, G.K., Alladi, S., Bak, T.H., Shailaja, M., Mamidipudi, A., Rajan, A., Gollahalli, D., Chaudhuri, J.R., Kaul, S., 2014. Dementia in developing countries: Does education play the same role in India as in the West?. Dement neuropsychol. 8, 132-140.

Kertesz, A., 2003. Pick Complex: an integrative approach to frontotemporal dementia: primary progressive aphasia, corticobasal degeneration, and progressive supranuclear palsy. The neurologist. 9, 311-317.

Litvan, I., Agid, Y., Calne, D., Campbell, G., Dubois, B., Duvoisin, R.C., Goetz, C.G., Golbe, L.I., Grafman, J., Growdon, J.H., Hallett, M., 1996. Clinical research criteria for the diagnosis of progressive supranuclear palsy (SteeleRichardson-Olszewski syndrome) report of the NINDS-SPSP international workshop. Neurology. 47, 1-9.

Mohanty, A.K., 1994. Bilingualism in a multilingual society: Psycho-social and pedagogical implications. Central Institute of Indian Languages.

Naik, S., Bapi Raju, S., Vasanta, D., Alladi, S., Rajan, A., Gollahalli, D R., 2016. Understanding multilingualism in language contact situtations: A cluster analysis approach. Pre-conference proceedings of the International conference on Indian languages in contact situations: Historical, typological and sociolinguistic perspectives; Deccan College, Pune. p. 161-168.

Neary, D., Snowden, J.S., Gustafson, L., Passant, U., Stuss, D., Black, S., Freedman, M., Kertesz, A., Robert, P.H., Albert, M., Boone, K., Miller, B.L., Cummings, J., 
Benson, D.F., 1998. Frontotemporal lobar degeneration: A consensus on clinical diagnostic criteria. Neurology. 51, 1546-1554.

Ossher, L., Bialystok, E., Craik, F.I., Murphy, K.J., Troyer, A.K., 2013. The effect of bilingualism on amnestic mild cognitive impairment. The Journals of

Gerontology Series B: Psychological Sciences and Social Sciences. 68, 8-12.

Premi, E., Gazzina, S., Bozzali, M., Archetti, S., Alberici, A., Cercignani, M., Bianchetti, A., Gasparotti, R., Turla, M., Caltagirone, C., Padovani, A., 2013. Cognitive reserve in granulin-related frontotemporal dementia: from preclinical to clinical stages. PloS one. 8, e74762.

Rascovsky, K., Hodges, J.R., Knopman, D., Mendez, M.F., Kramer, J.H., Neuhaus, J., Van Swieten, J.C., Seelaar, H., Dopper, E.G.P., Onyike, C.U., Hillis, A.E., Josephs, K.A., Boeve, B.F., Kertesz, A., Seeley, W.W., Rankin, K.P., Johnson, J.K., Gorno-Tempini, M.L., Rosen, H., Prioleau-Latham, C.E., Lee, A., Kipps, C.M., Lillo, P., Piguet, O., Rohrer, J.D., Rossor, M.N., Warren, J.D., Fox, N.C., Galasko, D., Salmon, D.P., Black, S.E., Mesulam, M., Weintraub, S., Dickerson, B.C., Diehl-Schmid, J., Pasquier, F., Deramecourt, V., Lebert, F., Pijnenburg, Y., Chow, T.W., Manes, F., Grafman, J., Cappa, S.F., Freedman, M., Grossman, M., Miller, B.L., 2011. Sensitivity of revised diagnostic criteria for the behavioural variant of frontotemporal dementia. Brain. 134, 2456-2477.

Seeley, W.W., Crawford, R., Rascovsky, K., Kramer, J.H., Weiner, M., Miller, B.L., Gorno-Tempini, M.L., 2008. Frontal paralimbic network atrophy in very mild behavioral variant frontotemporal dementia. Archives of neurology. 65, 249-255.

Sha, S., Hou, C., Viskontas, I.V., Miller, B.L., 2006. Are frontotemporal lobar degeneration, progressive supranuclear palsy and corticobasal degeneration distinct diseases?. Nat Clin Pract Neurol. 2, 658-665.

Sharp, E.S., Gatz, M., 2011. The relationship between education and dementia an updated systematic review. Alzheimer Dis Assoc Disord. 25, 289-304.

Stern, Y., 2002. What is cognitive reserve? Theory and research application of the reserve concept. J. Int. Neuropsychol. Soc. 8, 448-460.

Strong, M.J., Grace, G.M., Freedman, M., Lomen-Hoerth, C., Woolley, S., Goldstein, L.H., Murphy, J., Shoesmith, C., Rosenfeld, J., Leigh, P.N., Bruijn, L., 2009. Consensus criteria for the diagnosis of frontotemporal cognitive and behavioural syndromes in amyotrophic lateral sclerosis. Amyotrophic Lateral Sclerosis. 10, 131-146.

Valian, V., 2015. Bilingualism and cognition: A focus on mechanisms. Bilingualism: Language and Cognition. 18, 47-50.

Vasanta, D., 2011. (Re)searching multilingualism in India: a critical review of concepts. Journal of Indian Speech and Hearing Association. 25, 71-81. 
Vega-Mendoza, M., West, H., Sorace, A., Bak, T.H., 2015. The impact of late, nonbalanced bilingualism on cognitive performance. Cognition. 137, 40-46.

Woumans, E., Santens, P., Sieben, A., Versijpt, J., Stevens, M. and Duyck, W., 2015. Bilingualism delays clinical manifestation of Alzheimer's disease. Bilingualism: Language and Cognition. 18, 568-574.

Zahodne, L.B., Schofield, P.W., Farrell, M.T., Stern, Y., Manly, J.J., 2014. Bilingualism does not alter cognitive decline or dementia risk among Spanishspeaking immigrants. Neuropsychology. 28, 238. 
Table 1: Clinical and demographic profiles of FTD subtypes

\begin{tabular}{|c|c|c|c|c|c|c|c|}
\hline & $\begin{array}{l}\text { bvFTD } \\
(n=67)\end{array}$ & $\begin{array}{l}\text { PNFA } \\
(n=39)\end{array}$ & $\begin{array}{l}\text { SD } \\
(n=23)\end{array}$ & $\begin{array}{l}\begin{array}{l}\text { FTD-MND } \\
(\mathbf{n}=10)\end{array} \\
\end{array}$ & $\begin{array}{l}\text { CBD } \\
(n=23)\end{array}$ & $\begin{array}{l}\text { PSP } \\
(n=31)\end{array}$ & p Value \\
\hline $\begin{array}{l}\text { Age at } \\
\text { presentation }\end{array}$ & $61.8(10.4)$ & $64.9(8.6)$ & $63.5(10.8)$ & $56.4(7.9)$ & $62.3(7.2)$ & $65.4(8.7)$ & 0.089 \\
\hline Age at onset & $58.8(10.3)$ & $62.1(7.9)$ & $60.6(10.5)$ & $54.3(7.9)$ & $60.7(7.3)$ & $63.6(8.4)$ & 0.046 \\
\hline $\begin{array}{l}\text { Duration of } \\
\text { illness }\end{array}$ & $3.0(2.3)$ & $2.8(2.0)$ & $2.8(1.8)$ & $2.0(1.4)$ & $1.5(0.9)$ & $1.8(1.1)$ & $0.003^{\mathrm{a}}$ \\
\hline Sex, Male & $33(49.3 \%)$ & $26(66.7 \%)$ & $9(39.1 \%)$ & $7(70 \%)$ & $17(73.9 \%)$ & $19(61.3 \%)$ & 0.083 \\
\hline Bilinguals & $41(61.2 \%)$ & $22(56.4 \%)$ & $17(73.9 \%)$ & $5(50.0 \%)$ & $16(69.6 \%)$ & $20(64.5 \%)$ & 0.676 \\
\hline Literacy & $61(91.0 \%)$ & $37(94.9 \%)$ & $20(87.0 \%)$ & $9(90.0 \%)$ & $20(87.0 \%)$ & $25(80.6 \%)$ & 0.533 \\
\hline $\begin{array}{l}\text { Years of } \\
\text { education }\end{array}$ & $11.3(5.8)$ & $10.9(5.3)$ & $11.4(5.2)$ & $11.0(5.6)$ & $12.7(6.3)$ & $10.9(6.7)$ & 0.884 \\
\hline $\begin{array}{ll}\text { CDR } \\
\text { - } & \text { Mild } \\
\text { - } & \text { Moderate } \\
\text { - } & \text { Severe }\end{array}$ & $\begin{array}{l}41(61.2 \%) \\
19(28.4 \%) \\
7(10.4 \%)\end{array}$ & $\begin{array}{l}24(63.2 \%) \\
13(34.2 \%) \\
1(2.6 \%)\end{array}$ & $\begin{array}{l}14(60.9 \%) \\
8(34.8 \%) \\
1(4.3 \%)\end{array}$ & $\begin{array}{l}6(66.7 \%) \\
2(22.2 \%) \\
1(11.1 \%)\end{array}$ & $\begin{array}{l}17(73.9 \%) \\
5(21.7 \%) \\
1(4.3 \%)\end{array}$ & $\begin{array}{l}26(86.7 \%) \\
4(13.3 \%) \\
0(0.0 \%)\end{array}$ & 0.310 \\
\hline $\begin{array}{l}\text { Family } \\
\text { history of } \\
\text { dementia } \\
\text { MMSE }\end{array}$ & $23(34.3 \%)$ & $7(17.9 \%)$ & $0(0.0 \%)$ & $1(10 \%)$ & $3(13.0 \%)$ & $4(12.9 \%)$ & 0.005 \\
\hline ACE-R & $51.2(31.9)$ & $48.9(34.3)$ & $40.0(24.8)$ & $46.4(25.7)$ & $57.0(30.7)$ & $65.2(23.7)$ & 0.158 \\
\hline
\end{tabular}

Abbreviations: bvFTD = behavioral variant frontotemporal dementia; $\mathrm{PNFA}=$ progressive non fluent aphasia; $\mathrm{SD}=$ semantic dementia; FTD-MND= frontotemporal dementia- motor neuron disease; $\mathrm{CBD}=$ cortico basal degeneration; $\mathrm{PSP}=$ progressive supranuclear palsy; $\mathrm{CDR}=$ clinical dementia rating; $\mathrm{MMSE}=$ Mini mental state examination; ACE-R = Addenbrooke's cognitive examination-Revised;

Data are mean $\pm \mathrm{SD}$, or $\mathrm{n}(\%)$

a Duration of illness bvFTD $>$ CBD and PSP 
Table 2: Demographic and clinical characteristics of monolingual and bilingual patients with FTD.

\begin{tabular}{|c|c|c|c|}
\hline & $\begin{array}{l}\text { Monolingual } \\
(\mathrm{n}=72,37.3 \%)\end{array}$ & $\begin{array}{l}\text { Bilingual } \\
(\mathrm{n}=121,62.7 \%)\end{array}$ & p Value \\
\hline Sex (male:female, \%) & $34: 38(47.2 \%: 52.8 \%)$ & $77: 44(63.6 \%: 36.4 \%)$ & 0.036 \\
\hline Literacy & $53(73.6 \%)$ & $119(98.3 \%)$ & $<0.0001$ \\
\hline Years of education & $6.9 \pm 5.3$ & $13.9 \pm 4.3$ & $<0.0001$ \\
\hline $\begin{aligned} & \text { Occupation }^{\text {a }} \\
& \text { - } \text { Elementary } \\
& \text { - } \text { Skilled, Clerical } \\
& \text { - } \text { Professionals }\end{aligned}$ & $\begin{array}{l}9(28.1 \%) \\
18(56.2 \%) \\
5(15.6 \%)\end{array}$ & $\begin{array}{l}8(10.4 \%) \\
35(45.5 \%) \\
34(44.2 \%)\end{array}$ & 0.006 \\
\hline Urban $^{b}$ & $30(49.2 \%)$ & $88(75.9 \%)$ & 0.001 \\
\hline Age at presentation (years) & $61.0 \pm 9.5(41-82)$ & $64.2 \pm 9.4(40-91)$ & 0.028 \\
\hline Age at onset (years) & $58.4 \pm 9.3(41-82)$ & $61.7 \pm 9.1(39-89)$ & 0.017 \\
\hline Duration of illness, years & $2.6 \pm 2.3$ & $2.4 \pm 1.7$ & 0.505 \\
\hline MMSE & $15.9 \pm 10.3$ & $18.1 \pm 10.2$ & 0.155 \\
\hline ACE-R & $48.0 \pm 30.1$ & $53.7 \pm 31.0$ & 0.210 \\
\hline $\begin{array}{cl}\text { CDR }^{\mathbf{c}} & \\
\text { - } & \text { Mild } \\
\text { - } & \text { Moderate } \\
\text { - } & \text { Severe }\end{array}$ & $\begin{array}{l}45(63.4 \%) \\
21(29.6 \%) \\
5(7.0 \%)\end{array}$ & $\begin{array}{l}83(69.7 \%) \\
30(25.2 \%) \\
6(5.0 \%)\end{array}$ & 0.641 \\
\hline Family history of dementia & $14(19.4 \%)$ & $24(19.8 \%)$ & 0.911 \\
\hline
\end{tabular}

Abbreviations: $\mathrm{MMSE}=$ Mini mental state examination; ACE-R = Addenbrooke's cognitive examination-revised; $\mathrm{CDR}=$ clinical dementia rating

Data are mean $\pm \mathrm{SD}$, range, or $\mathrm{n}(\%)$

${ }^{a}$ Monolinguals $n=52$, bilinguals $n=94$, missing data $n=47$ (housewives $n=37$, excluded from occupational status analysis)

${ }^{b}$ Monolinguals $n=61$, bilinguals $n=116$, missing data $=16$

${ }^{\mathrm{c}}$ Monolinguals $\mathrm{n}=71$, bilinguals $\mathrm{n}=119$, missing data $=3$ 
Table 3: Relationship between bilingualism with age at onset of dementia in FTD subtypes

\begin{tabular}{cllll}
\hline FTD Subtype & $\begin{array}{c}\text { Mono vs } \\
\text { Bilingual, } \mathbf{n}\end{array}$ & $\begin{array}{c}\text { Monolingual } \\
(\mathbf{n}=\mathbf{7 2})\end{array}$ & $\begin{array}{c}\text { Bilingual } \\
(\mathbf{n = 1 2 1})\end{array}$ & P Value \\
\hline bvFTD & $26: 41$ & $55.3(10.6)$ & $61.0(9.6)$ & 0.024 \\
PNFA & $17: 22$ & $61.7(6.3)$ & $62.4(9.1)$ & 0.792 \\
SD & $6: 17$ & $60.3(9.9)$ & $60.8(11.0)$ & 0.921 \\
FTD-MND & $5: 5$ & $52.8(11.1)$ & $55.8(3.3)$ & 0.578 \\
CBD & $7: 16$ & $60.4(6.3)$ & $60.8(7.8)$ & 0.903 \\
PSP & $11: 20$ & $60.8(8.6)$ & $65.1(8.2)$ & 0.176 \\
\hline
\end{tabular}

Abbreviations: bvFTD= behavioral variant frontotemporal dementia; PNFA=progressive non fluent aphasia; $\mathrm{SD}=$ semantic dementia; FTD-MND= frontotemporal dementia- motor neuron disease $\mathrm{CBD}=$ cortico basal degeneration; PSP = progressive supranuclear palsy;

Data are presented as mean (SD); unless otherwise stated. 